\title{
EXPORTAÇÕES BRASILEIRAS DE RECURSOS NATURAIS NÃO RENOVÁVEIS: COMPETITIVIDADE E PADRÕES DE ESPECIALIZAÇÃO' ${ }^{1}$
}

\author{
Henrique dos Santos Maxir ${ }^{2}$ \\ Rosane Nunes de Faria ${ }^{3,4}$
}

Resumo: A presente pesquisa teve como objetivo analisar a dinâmica das exportações brasileiras de Recursos Naturais Não Renováveis (RNNR) entre o período de 2000 a 2012. Para tal, foram utilizados o indicador de Vantagens Comparativas Reveladas (VCR) e o modelo de Constant Market Share (CMS). Os resultados mostraram que o Brasil apresentou Vantagens Comparativas Reveladas nas exportações de RNNR em todo o período, porém essas vantagens estão concentradas em minérios, escórias e cinzas, e ferro fundido, ferro e aço. Verificou-se aumento contínuo do indicador de VCR para combustíveis minerais, óleos e ceras minerais, o que indica tendência de mudança de uma situação de desvantagem para vantagem comparativa revelada para essa categoria nos próximos anos. Por outro lado, o Brasil reduziu suas vantagens comparativas nas exportações de alumínio e suas obras e, a partir de 2010, passou a apresentar desvantagem nessa categoria. O principal efeito responsável pelo crescimento das exportações brasileiras de RNNR foi a composição da pauta de exportação, sendo o efeito competitividade predominante apenas no período 2000-2003, caracterizado pela desvalorização cambial no Brasil.

Palavras-chave: recursos naturais não renováveis; exportações; competitividade; vantagem comparativa.

1 Recebido em: 25/03/2014; Aceito em: 20/08/2014

2 Mestrando em Economia Aplicada na Escola Superior de Agricultura "Luiz de Queiroz" da Universidade de São Paulo (ESALQ-USP). E-mail: henriquemaxir@usp.br

3 Professora do Departamento de Economia da Universidade Federal de São Carlos (UFSCar). E-mail: rnfaria@ ufscar.br

4 Os autores agradecem à Fapesp (2012/05891-8) o financiamento desta pesquisa. 
Abstract: The purpose of this research is to analyze the dynamics of Brazilian exports of Non-Renewable Natural Resources (NRNR) over the period 2000-2012. The Revealed Comparative Advantage Index (RCA) and the Constant Market Share model (CMS) were calculated and the results showed that Brazil presented Revealed Comparative Advantage in exhaustible natural resource exports over the period, but these advantages were concentrated in ores, slag and ash; and iron and steel. It was found continuous increase in the VCR index for mineral fuels, distillation products etc., suggesting a shift in trend of comparative disadvantages for revealed comparative advantage in the next years. On the other hand, Brazil has reduced comparative advantages in exports of aluminum and articles thereof, presenting comparative disadvantages between 2010 and 2012. The commodity effect was the main factor contributing to the growth of Brazilian RNNR exports between 2004 and 2012, and the competitiveness effect was the main factor driving the growth of Brazilian NRNR exports from 2000 to 2003, characterized by the currency devaluation in Brazil.

Keywords: non-renewable natural resources; exports; competitiveness; comparative advantage.

\section{Introdução}

As exportações brasileiras aumentaram significativamente na última década e a participação do Brasil no volume do comércio mundial passou de $0,90 \%$, em 2000, para $1,55 \%$, em 2012. A taxa de crescimento das exportações brasileiras neste período foi de $340 \%$, tendo o valor das exportações passado de 55,1 bilhões de dólares, em 2000, para 242,5 bilhões de dólares, em 2012. Esse crescimento significativo resultou principalmente das exportações brasileiras de Recursos Naturais Não Renováveis (RNNR) ${ }^{5}$, que se expandiram a uma taxa de $635 \%$ no mesmo período, aumentando assim sua participação na balança comercial brasileira de 18,77\%, em 2000, para 31,9\%, em 2012 (MDIC, 2012).

5 Os Recursos Naturais Não Renováveis (RNNR) são materiais existentes no meio ambiente, que são tanto escassos como úteis economicamente na produção ou no consumo; são produtos como minérios em geral e os combustíveis fósseis como petróleo e gás natural (SILVA, 2006; WORLD TRADE ORGANIZATION - WTO, 2010). 
Essa crescente e expressiva contribuição dos RNNR nas exportações brasileiras suscita a questão de pesquisa que se pretende investigar neste artigo: quais os principais drivers do crescimento das exportações brasileiras de RNNR?

O objetivo desse artigo é analisar o desempenho das exportações brasileiras de Recursos Naturais Não Renováveis (RNNR), desagregadas por categorias de produtos, no período compreendido entre 2000 e 2012. $\mathrm{O}$ artigo apresenta uma análise da evolução das vantagens comparativas reveladas e identifica as principais fontes de crescimento das exportações brasileiras de RNNR.

Embora exista uma literatura recente sobre a análise do desempenho das exportações brasileiras para diferentes produtos agrícolas e manufaturados (SEREIA; NOGUEIRA; CÂMARA, 2002; DIETER; ENGLERT, 2006; DIZ, 2008; VITTI, 2009; CHANG, 2011; GOMES, 2011; SILVA et al., 2012), não foram encontrados na literatura trabalhos que analisassem exclusivamente o comportamento das exportações de Recursos Naturais Não Renováveis (RNNR). Portanto, o presente trabalho busca preencher esse gap na literatura empírica ao prover informações desagregadas por categorias de produtos classificados como RNNR.

O artigo está dividido em mais quatro seções, além desta introdução, sendo elas a revisão da literatura teórica sobre comércio internacional e recursos naturais, a metodologia, os resultados e as conclusões.

\section{Comércio internacional de recursos naturais não renováveis: Aspectos teóricos}

A teoria tradicional de comércio internacional estabelece que os países se especializam na produção de bens em que têm vantagem comparativa (KRUGMAN; OBSTFELD, 2010; MARKUSEN et al., 1995). No modelo de Hecksher-Ohlin (HO), as vantagens comparativas são 
determinadas por diferenças de dotação de fatores de produção, sendo assim, as nações exportam os bens intensivos nos fatores de produção em que são relativamente abundantes. Dessa forma, a distribuição geográfica desigual de recursos naturais pode desempenhar um papel importante na explicação do comércio internacional, e as nações abundantes em recursos naturais tendem a exportar bens cuja produção utiliza intensivamente esses recursos.

Wood e Berge (1997), em uma versão modificada do modelo de HecksherOhlin, consideram os recursos naturais e os recursos humanos como fatores de produção e concluem que os países com alta relação recursos humanos/recursos naturais têm vantagem comparativa na produção de manufaturas e aqueles com baixa relação recursos humanos/recursos naturais têm vantagem comparativa na produção primária.

Embora a dotação de recursos naturais possa representar uma condição necessária para a produção e exportação desses recursos e/ou de bens intensivos nesses recursos, ela não é uma condição suficiente. Outros fatores tais como custos de transporte, economias de escala, tecnologia etc. podem alterar as vantagens comparativas dos países e afetar o padrão de comércio de recursos naturais (WORLD TRADE ORGANIZATION - WTO, 2010).

De fato, tem sido observada a existência de comércio intraindústria para alguns recursos naturais e seus derivados, como, por exemplo, o caso do Chile, que exporta concentrado de cobre para o Peru, mas também importa esse concentrado do Peru (DAVIS, 2010).

O comércio intraindústria pode resultar dos altos custos de transporte e/ ou da estrutura de mercado de oligopólio. Sob condição de altos custos de transportes, um país A poderia importar minério de ferro de um país B, localizado em sua fronteira, e exportá-lo para outras regiões do país B onde exista capacidade de fundição instalada. No caso de prevalência de uma estrutura oligopolista da indústria mineradora doméstica, o cartel dominante estabelece os preços mais baixos no mercado internacional e maximiza o markup no mercado doméstico. Dessa forma, as firmas 
dominantes exportam minérios e outros bens intensivos, e as firmas da franja, que competem entre si, importam o minério concentrado a preços mais baixos no mercado internacional para produzir os bens intensivos no recurso e exportá-los (DAVIS, 2010).

Ademais, Davis (2010) argumenta que a redução dos custos de transporte faz com que recursos imóveis passem a ser comercializados como matérias-primas minimamente processadas, o que modifica as vantagens comparativas das nações envolvidas no comércio internacional. A migração da indústria de base da Europa e dos Estados Unidos para países pobres em recursos naturais, como Japão e Coreia do Sul, pode ser se explicada pelo fenômeno da redução dos custos de transporte.

\section{Metodologia}

\section{O Indicador de vantagens comparativas reveladas}

Criado por Bela Balassa em 1965, o indicador de Vantagens Comparativas Reveladas (VCR) parte do pressuposto de que um país tende a se especializar nas exportações de produtos em que ele apresenta vantagens competitivas. $\mathrm{O}$ indicador revela se algum produto apresenta vantagem nas exportações se comparado ao total da pauta de exportações de um país ou região. Os produtos considerados competitivos devem apresentar indicador superior a um (1), o que evidencia que a participação do produto na pauta de exportação do país é maior que a participação do país nas exportações mundiais (DIZ, 2008; CORONEL, 2008). O indicador de Vantagens Comparativas Reveladas (VCR) pode ser calculado da seguinte maneira:

$$
V C R=\frac{\frac{X_{i j}}{X_{i k}}}{\frac{X_{j}}{X_{k}}}
$$


Em que,

$X_{i j}=$ valor das exportações do i-ésimo produto (RNNR) do j-ésimo país (Brasil);

$X_{i k}=$ valor das exportações do i-ésimo produto (RNNR) do k-ésimo conjunto de referência (Mundo);

$X_{j}=$ valor total das exportações do j-ésimo país (Brasil); e

$X_{k}=$ valor total das exportações do k-ésimo conjunto de referência (Mundo).

Portanto, se:

$V C R<1$, a j-ésima região ou país não tem vantagem comparativa revelada; $V C R>1$, a j-ésima região ou país tem vantagem comparativa revelada; e $V C R=1$, a j-ésima região ou país não tem vantagem e nem desvantagem comparativa.

Segundo Ribeiro (2008), o VCR "revela" as vantagens comparativas, ponderando os resultados encontrados depois de ter ocorrido o comércio entre regiões. Quanto mais alto o indicador, maior será a vantagem comparativa do país no comércio internacional.

\section{Modelo Constant Market Share}

O modelo de Constant Market Share, desenvolvido por Leamer e Stern em 1970, tem sido utilizado na literatura para decompor as variações nas exportações de um país em diferentes efeitos, sendo o efeito competitividade avaliado pela diferença entre as mudanças observadas nas exportações e o aumento hipotético esperado se o país tivesse mantido sua parcela de mercado no comércio global (SEREIA; NOGUEIRA; CAMARA, 2002; DIZ, 2008; CHANG, 2011). 
Desta maneira, assumindo que os valores exportados utilizados para o cálculo do Constant Market Share (CMS) correspondem a pontos discretos no tempo e que as exportações não são diferenciadas por produtos, chega-se à seguinte identidade:

$$
V^{\prime} . .-V . . \equiv r V . .+\left(V^{\prime} . .-V . .-r V . .\right)
$$

Em que,

$V . .=$ valor total das exportações do país $\mathrm{Z}$ no período 1 ;

$V^{\prime} . .=$ valor total das exportações do país $\mathrm{Z}$ no período 2 ;

$r=$ incremento das exportações mundiais do período 1 para o período 2 .

Portanto, de acordo com a identidade (2), a variação das exportações do país $\mathrm{Z}$ de um período a outro está associada à variação das exportações mundiais (a) e a um efeito residual que se assume como competitividade (b). Se assumirmos que as exportações do país Z são compostas por i-ésimos produtos, temos a "análise de segundo nível", que é representada pela identidade a seguir:

$V_{i .}^{\prime}-V_{i .} \equiv r_{i .} V_{i .}+\left(V_{i .}^{\prime}-V_{i .}-r_{i .} V_{i .}\right)$

que pode ser rearranjada da seguinte forma:

$\mathrm{V}^{\prime} . .-\mathrm{V} . . \equiv \sum_{i} \mathrm{r}_{i .} \mathrm{V}_{i .}+\sum_{i}\left(\mathrm{~V}_{i .}^{\prime}-\mathrm{V}_{i .}-r_{i .} \mathrm{V}_{i .}\right) \equiv \mathrm{rV} . .+\sum_{i}\left(\mathrm{r}_{i}-\mathrm{r}\right) \mathrm{V}_{i .}+\sum_{i}\left(\mathrm{~V}_{i .}^{\prime}-V_{i .}-r_{i .} \mathrm{V}_{i .}\right)$

(a) (b) 
$i=$ produto;

$V_{i .}=$ valor total das exportações do i-ésimo produto do país $\mathrm{Z}$ no período 1;

$V_{i .}^{\prime}=$ valor total das exportações do i-ésimo produto do país $\mathrm{Z}$ no período 2 ;

$r_{i}=$ incremento das exportações mundiais do i-ésimo produto do período 1 para o período 2 .

De acordo com a identidade (4), a variação das exportações do país Z pode ser decomposta em três efeitos:

(a) O Efeito Crescimento do Comércio Mundial rV.., que representa o crescimento das exportações do país $\mathrm{Z}$ devido ao crescimento das exportações mundiais;

(b) $\mathrm{O}$ Efeito Composição da Pauta de Exportações $\sum_{i}\left(\mathrm{r}_{i}-\mathrm{r}\right) \mathrm{V}_{i .}$, que representa o crescimento das exportações devido à mudanças na estrutura da pauta de exportação, ou seja, se as exportações mundiais do bem (i) aumentar mais que a média mundial para todas as mercadorias exportadas, $\left(\mathrm{r}_{i}-\mathrm{r}\right)$ torna-se positivo e se o peso de $\mathrm{V}_{i}$. for significativo, tem-se as exportações do país $Z$ são explicadas pela crescente demanda mundial por tal bem $(i)$;

(c) O Efeito Competitividade ou residual $\sum_{i}\left(\mathrm{~V}_{i .}^{\prime}-V_{i .}-r_{i .} \mathrm{V}_{i .}\right)$ , representa a diferença entre o crescimento das exportações que ocorreria se o país Z mantivesse a parcela de exportação de cada bem (i) e o crescimento vigente de acordo com parcela de exportação atual. Se o efeito for negativo significa que o país $Z$ perdeu sua parcela de mercado e a relação de preços entre o exterior e o país $Z$ tornou-se desfavorável, ou seja, os preços do bem (i) exportado pelo país $Z$ são maiores que os preços vigentes no comércio internacional. 
Definição de recursos naturais não renováveis

No presente artigo, os Recursos Naturais Não Renováveis (RNNR) são definidos como recursos formados por processos geológicos lentos e, portanto, extraídos mais rapidamente do que reabastecidos por processos naturais. Pode-se assumir que são recursos com estoque fixo, ou seja, existe uma quantidade finita na superfície da terra. Os RNNR incluem fontes de energia como o petróleo, o gás natural, o urânio e o carvão, e também incluem os minerais não energéticos, como o cobre, o níquel, a bauxita, o zinco, entre outros (HARTWICK; OLEWILER, 1986; SILVA, 2006; WORLD TRADE ORGANIZATION - WTO, 2010). A Tabela 1 apresenta a classificação dos bens exportados pelo Brasil, que se encaixam na definição de RNNR, segundo o World Trade Report (2010), de maneira desagregada, por capítulos do Sistema Harmonizado (SH) de Mercadorias.

Tabela 1 - Recursos naturais não renováveis exportados, desagregados por capítulo - SH.

\begin{tabular}{cl}
\hline $\begin{array}{c}\text { Capítulos } \\
- \text { SH }\end{array}$ & Descrição \\
\hline 25 & Sal; Enxofre; Terras e pedras; Gesso, cal e cimento. \\
26 & Minérios, escórias e cinzas. \\
27 & Combustíveis minerais, Óleos minerais e produtos da sua \\
72 & destilação; Matérias betuminosas; Ceras Minerais. \\
73 & Ferro fundido, ferro e aço. \\
74 & Obras de ferro fundido, ferro ou aço. \\
75 & Níque e e suas obras. \\
76 & Alumínio e suas obras. \\
78 & Chumbo e suas obras. \\
79 & Zinco e suas obras. \\
80 & Estanho e suas obras. \\
81 & Outros Metais Comuns: Ceramais (“cermets”); Obras \\
\hline
\end{tabular}

Fonte: Aliceweb2 - Ministério do Desenvolvimento, Indústria e Comércio Exterior - MDIC. 
Os capítulos selecionados representam tanto os Recursos Naturais Não Renováveis em estado bruto, como, por exemplo, os produtos dos capítulos 25, 26 e 27, assim como produtos elaborados a partir da matéria-prima (chapas, barras, tubos, folhas, fios etc.), denominados "suas obras", e que aparecem em vários capítulos como 79, 80, 81 etc. Dessa forma, apesar de a agregação por capítulo ser adequada para a análise proposta, deve-se atentar para o fato de que produtos com características distintas são analisados conjuntamente no que concerne à sua inserção no mercado internacional ${ }^{6}$.

\section{Fonte de Dados}

Os dados referentes às exportações brasileiras de RNNR foram obtidos no sistema Aliceweb2, desenvolvido pela Secretaria do Comércio Exterior (Secex), do Ministério do Desenvolvimento, Indústria e Comércio Exterior (MDIC). Os dados referentes às exportações mundiais foram obtidos na Seção Estatística de Comércio Internacional de Mercadorias (International Merchandise Trade Statistics Section - IMTSS), da Divisão Estatística das Nações Unidas (United Nations Statistics Division - UNSD). O período de análise compreende os anos de 2000 a 2012 e pode ser justificado pela rápida ascensão das exportações brasileiras de RNNR para o resto do mundo, assim como por se tratar de um período de significativo crescimento das exportações mundiais.

6 O detalhamento dos produtos desagregados a 6 dígitos do Sistema Harmonizado de Classificação de Mercadorias pode ser encontrado no site http://www.mdic.gov.br/arquivos/ dwnl 1403725110.doc. 


\section{Resultados e discussão}

As exportações brasileiras de recursos naturais não renováveis

A Figura 1 mostra a evolução das exportações brasileiras de Recursos Naturais Não Renováveis, desagregadas por capítulos, do Sistema Harmonizado (SH-2 dígitos), para o período de 2000 a 2012. É possível verificar tendência de aumento significativo do valor das exportações brasileiras de combustíveis minerais, óleos minerais e produtos de sua destilação, matérias betuminosas, ceras minerais (capítulo 27) assim como minérios, escórias e cinzas (capítulo 26).

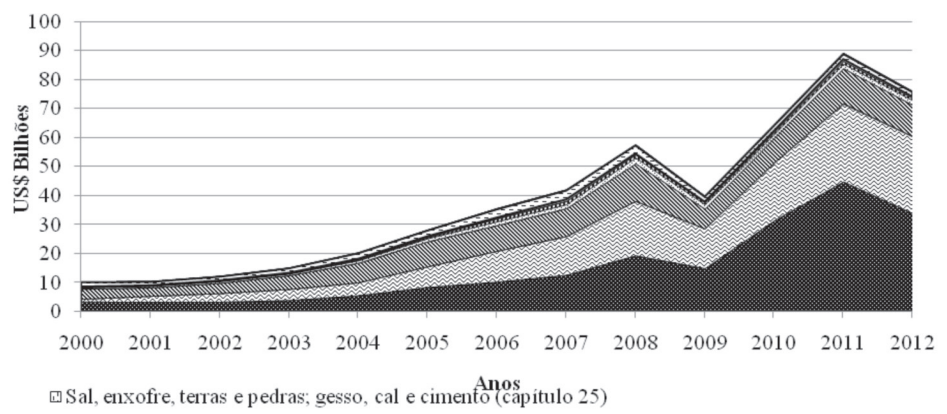

睴 Minérios, escórias e cinzas (capitulo 26)

: Combustiveis minerais, óleos minerais e produtos da sua destilação; Matérias betuminosas; Ceras Minerais(capitulo 27)

S Ferro fundido, ferro e aço (capitulo 72)

圆 Obras de ferro fundido, ferro ou aço (capitulo 73)

III Cobre e suas obras (capitulo 74)

$\square$ Niquel e suas obras (capitulo 75)

몬 Aluminio e suas obras (capitulo 76)

․․․ Chumbo e suas obras (capitulo 78)

-Zinco e suas obras (capitulo 79)

שEstanho e suas obras (capitulo 80)

目 Outros Metais Comuns: Ceramais ("cermets"); Obras dessas matérias (capitulo 81)

Figura 1 - Exportações brasileiras de recursos naturais não renováveis no período de 2000 a 2012.

Fonte: Elaboração própria tendo por base dados do Aliceweb2. 
A Figura 2 mostra a participação de cada categoria nas exportações totais de RNNR. Observam-se reduções significativas da participação das exportações brasileiras de ferro fundido, ferro e aço, assim como alumínio e suas obras, que são capítulos que incluem também produtos processados. Verifica-se também maior concentração das exportações de RNNR nas categorias minério (capítulo 26) e combustíveis minerais (capítulo 27), que são representados principalmente por recursos naturais em seu estado bruto ou com mínimo processamento.

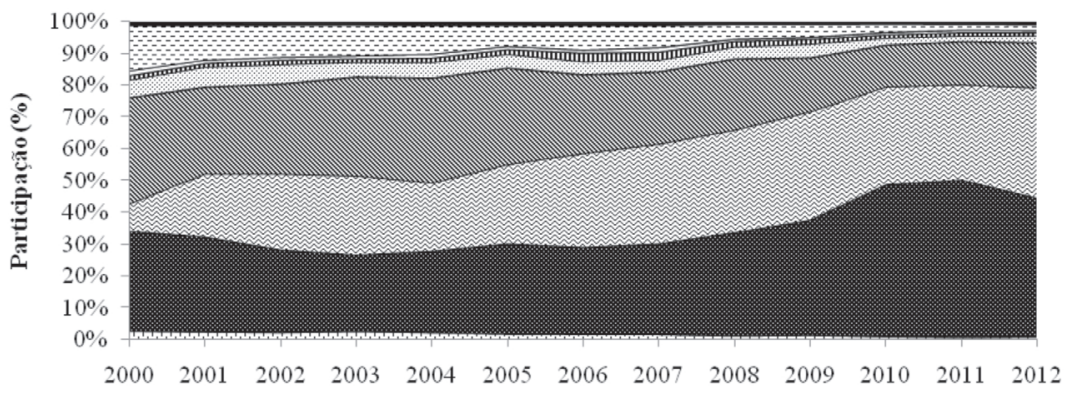

GSal, enxofre, terras e pedras; gesso, cal e cimento Anos (capitulo 25)

网Minérios, escórias e cinzas (capitulo 26)

@ Combustiveis minerais, óleos minerais e produtos da sua destilação; Matérias b etuminosas; Ceras

Minerais(capitulo 27)

$\mathbb{\$}$ Ferro fundido, ferro e aço (capitulo 72)

图Obras de ferro fundido, ferro ou aço (capitulo 73)

m Cobre e suas obras (capitulo 74)

$\square$ Niquel e suas obras (capitulo 75)

GAluminio e suas obras (capitulo 76)

g: Chumbo e suas obras (capitulo 78)

- Zinco e suas obras (capitulo 79)

Estanho e suas obras (capítulo 80)

目Outros Metais Comuns: Ceramais ("cermets"); Obras dessas matérias (capitulo 81)

Figura 2 - Participação das exportações de cada categoria nas exportações brasileiras de recursos naturais não renováveis.

Fonte: Elaboração própria tendo por base dados do Aliceweb2. 
Resultados do indicador de vantagens comparativas reveladas

A Tabela 2 revela que o Brasil apresentou VCR $>1$ para as exportações totais de RNNR ao longo de todo o período analisado, ou seja, o país tem se especializado nas exportações de tais produtos.

Tabela 2 - Vantagens comparativas reveladas das exportações brasileiras de recursos naturais não renováveis.

\begin{tabular}{cccccccccccccc}
\hline Ano & $\mathbf{2 0 0 0}$ & $\mathbf{2 0 0 1}$ & $\mathbf{2 0 0 2}$ & $\mathbf{2 0 0 3}$ & $\mathbf{2 0 0 4}$ & $\mathbf{2 0 0 5}$ & $\mathbf{2 0 0 6}$ & $\mathbf{2 0 0 7}$ & $\mathbf{2 0 0 8}$ & $\mathbf{2 0 0 9}$ & $\mathbf{2 0 1 0}$ & $\mathbf{2 0 1 1}$ & $\mathbf{2 0 1 2}$ \\
VCR & 1,09 & 1,07 & 1,27 & 1,21 & 1,10 & 1,08 & 1,10 & 1,09 & 1,06 & 1,16 & 1,31 & 1,29 & 1,11 \\
\hline
\end{tabular}

Fonte: Elaboração tendo por base dados do Aliceweb2 e UN-Comtrade.

Entretanto, a análise desagregada por categorias dos RNNR indica que as vantagens comparativas do Brasil em RNNR são concentradas em poucas categorias. A Figura 3 apresenta as categorias que tiveram melhor desempenho quanto ao indicador de VCR, ou seja, superior à unidade na maioria dos anos, enquanto a Figura 4 apresenta as categorias cujo desempenho foi desfavorável, o que significa VCR menor que a unidade em quase todo o período.

Pode ser observado que apenas duas categorias de RNNR apresentaram VCR $>1$ em todos os anos de análise, caso dos minérios, escórias e cinzas (capítulo 26) e ferro fundido, ferro e aço (capítulo 72), indicando que as vantagens comparativas do Brasil em RNNR foram concentradas nestas duas categorias de produtos. Verifica-se na Figura 3 que os maiores valores do indicador VCR foram observados para as exportações de minérios, escórias e cinzas (capítulo 26), cabendo destacar que em 2000 as exportações de minérios, escórias e cinzas representavam 5,9 \% das exportações brasileiras e em 2012, 13,70\% da pauta brasileira.

No caso das exportações de ferro fundido, ferro e aço (capítulo 72), observa-se, na Figura 3, que apesar de o Brasil apresentar VCR $>1 \mathrm{em}$ todo o período, o indicador vem diminuindo ao longo dos anos, o que é explicado pela redução da participação das exportações destes produtos 
em relação ao total exportado pelo Brasil, assim como pelo aumento da participação das exportações destes produtos na pauta de exportação mundial.

Verifica-se tendência de redução do VCR para as exportações de alumínio e suas obras (capítulo 76), que passou a ser menor que a unidade a partir de 2010. Essa perda de competitividade pode ser explicada principalmente pela redução da representatividade na pauta de exportação brasileira, que passou de 2,70\% em 2000 para 0,61\% em 2012.

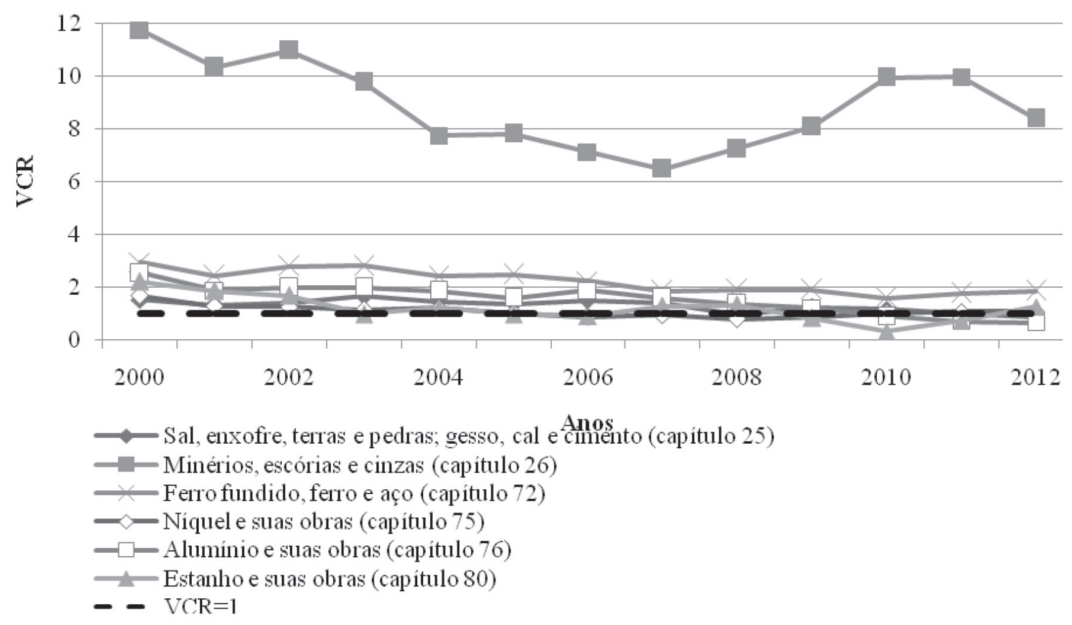

Figura 3 - Indicador de vantagens comparativas reveladas para os capítulos 25, 26, 72, 75, 76 e 80 .

Fonte: Elaboração própria tendo por base dados do Aliceweb2 e UN-Comtrade. 


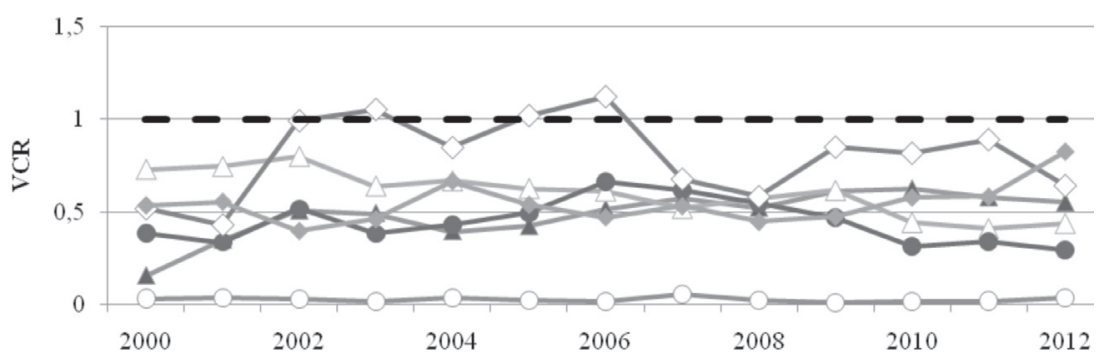

- Combustiveis minerais, óleos minerais e produtAdld\$s sua destilação; Matérias betuminosas; Ceras Minerais (capitulo 27)

Obras de ferro fundido, ferro ou aço (capitulo 73)

- Cobre e suas obras (capitulo 74)

- Chumbo esuas obras (capitulo 78)

$\longrightarrow$ Zinco e suas obras (capitulo 79)

$\longrightarrow$ Outros Metais Comuns: Ceramais ("cermets"); Obras dessas matérias (capitulo 81)

$-\quad \mathrm{VCR}=1$

Figura 4 - Indicador de vantagens comparativas reveladas para os capítulos $27,73,74,78,79$ e 81 .

Fonte: Elaboração própria tendo por base dados do Aliceweb2 e UN-Comtrade.

É relevante destacar que o Brasil apresentou desvantagens comparativas nas exportações de combustíveis minerais, óleos minerais e produtos da sua destilação, matérias betuminosas, ceras e minerais (capítulo 27). No entanto, o indicador apresentou tendência de crescimento ao longo do período analisado. De fato, as exportações dessa categoria aumentaram significativamente entre 2000 e 2012, provavelmente como resultado dos avanços brasileiros neste setor, sobretudo com o aumento da capacidade produtiva e a descoberta de novas bacias (Pré-Sal).

O Quadro 1 resume os resultados das Figuras 3 e 4 e apresenta uma classificação das categorias de produtos de acordo com as vantagens/ desvantagens comparativas. 
Quadro 1 - Vantagens e desvantagens comparativas reveladas das exportações brasileiras de recursos naturais não renováveis por categorias de produtos.

\begin{tabular}{|c|c|c|}
\hline $\begin{array}{c}\text { Vantagens } \\
\text { Comparativas } \\
\text { Reveladas } \\
(\mathbf{2 0 0 0 - 2 0 1 2 )} \\
\end{array}$ & $\begin{array}{l}\text { Vantagens Compara- } \\
\text { tivas Reveladas em } \\
\text { alguns anos de análise } \\
(2000-2012)\end{array}$ & $\begin{array}{l}\text { Desvantagens Com- } \\
\text { parativas Reveladas } \\
\qquad(2000-2012)\end{array}$ \\
\hline $\begin{array}{l}\text { - Minérios, } \\
\text { escórias e cinzas } \\
\text { (capítulo 26); } \\
\text { - Ferro fundido, } \\
\text { ferro e aço (capí- } \\
\text { tulo } 72 \text { ). }\end{array}$ & $\begin{array}{l}\text { - Sal, enxofre, terras, } \\
\text { pedras, gesso, cal e ci- } \\
\text { mento (capítulo 25); } \\
\text { - Níquel e suas obras } \\
\text { (capítulo 75); } \\
\text { - Alumínio e suas obras } \\
\text { (capítulo 76); } \\
\text { - Zinco e suas obras } \\
\text { (capítulo79); } \\
\text { - Estanho e suas obras } \\
\text { (capítulo 80). }\end{array}$ & $\begin{array}{l}\text { - Combustíveis mine- } \\
\text { rais, óleos minerais e } \\
\text { produtos da sua desti- } \\
\text { lação, matérias betumi- } \\
\text { nosas e ceras minerais } \\
\text { (capítulo 27); } \\
\text { - Obras de ferro fundi- } \\
\text { do, ferro ou aço (capítulo } \\
\text { 73); } \\
\text { - Cobre e suas obras } \\
\text { (capítulo74); } \\
\text { - Chumbo e suas obras } \\
\text { (capítulo 78); } \\
\text { - Outros metais co- } \\
\text { muns: ceramais (“cer- } \\
\text { mets”) e obras dessas } \\
\text { matérias (capítulo } 81 \text { ). }\end{array}$ \\
\hline
\end{tabular}

Fonte: Elaboração própria tendo por base dados do Aliceweb2 e UN-Comtrade.

\section{Resultados do modelo Constant Market Share}

Para o cálculo do modelo CMS, foi feita uma divisão de todo o tempo de análise em três períodos: Período I (2000-2003), Período II (20042008) e Período III (2009-2012). O Período I (2000-2003) pode ser caracterizado principalmente pela instabilidade da economia brasileira, com forte desvalorização da taxa de câmbio nominal, resultante da parada súbita do influxo de capitais estrangeiros no país, devido às eleições de 
2002. O Período II (2004-2008) é caracterizado pelo quadro internacional favorável, elevação dos termos de troca do país e pelo boom das exportações brasileiras, o que contribuiu para superávits em transações correntes durante todo o período. Finalmente, o Período III (2009-2012), denominado período pós-crise, é caracterizado por novas desvalorizações cambiais e queda no saldo da balança comercial, decorrentes da menor expansão das exportações em relação às importações.

Foi utilizado o modelo CMS de "segundo nível", em que o aumento do valor das exportações brasileiras de RNNR pode ser distribuído em três efeitos: i) Efeito Crescimento do Comércio Mundial (ECCM); ii) Efeito da Composição da Pauta de Exportações (ECPE); e iii) Efeito Competitividade (EC).

A Tabela 3 mostra que o Efeito Competitividade (EC) foi o mais relevante para o aumento das exportações brasileiras de RNNR no Período I, o que significa que o Brasil aumentou sua parcela no mercado internacional e que a relação de preços era favorável às exportações brasileiras. De fato, entre os anos 2000 a 2003, os preços dos produtos brasileiros exportáveis em dólares caíram significativamente, aumentando a competitividade do país em vários setores, inclusive nas categorias de RNNR, como mostram os resultados. Nos Períodos II e III, apesar de positivo, o EC passou a ter menor representatividade, e o Efeito Composição da Pauta de Exportação (ECPE) passou a ser o principal driver do crescimento das exportações brasileiras de RNNR, uma vez que a demanda internacional por esses recursos, especialmente a demanda chinesa, estava aquecida, e assim os países abundantes em tais recursos, como o Brasil, se beneficiaram com o aumento de tais exportações.

Destaca-se também que o Efeito Crescimento do Comércio Mundial (ECCM) foi o segundo principal agente responsável pelo crescimento das exportações brasileiras de RNNR nos três períodos. Ademais, o Efeito Competitividade (EC) é maior nos dois períodos que foram caracterizados por desvalorizações cambiais no Brasil (Períodos I e II), já que os preços dos produtos exportáveis caíram significativamente. 
Tabela 3 - O modelo Constant Market Share de segundo nível para variação das exportações brasileiras de recursos naturais não renováveis.

\begin{tabular}{cccccccc}
\hline Efeitos & $\begin{array}{c}\text { Período I (2000 } \\
\text { Variação em } \\
\text { USS FOB }\end{array}$ & $\begin{array}{c}\text { em } \\
\mathbf{\%}\end{array}$ & $\begin{array}{c}\text { Período II (2004 - 2008) } \\
\text { Variação em USS } \\
\text { FOB }\end{array}$ & $\begin{array}{c}\text { Período III (2009 - 2012) } \\
\text { em }\end{array}$ & $\begin{array}{c}\text { Variação em USS } \\
\text { FOB }\end{array}$ & $\begin{array}{c}\text { em } \\
\text { \% }\end{array}$ \\
$\begin{array}{c}\text { Efeito Crescimento } \\
\text { do Comércio } \\
\text { Mundial (ECCM) } \\
\text { Efeito Composição } \\
\text { da Pauta de }\end{array}$ & $1.954 .169 .245,92$ & 40,61 & $15.121 .972 .606,47$ & 40,60 & $12.466 .071 .121,11$ & 34,40 \\
$\begin{array}{c}\text { Exportacão (ECPE) } \\
\text { Efeito }\end{array}$ & $-43.720 .263,78$ & $-0,91$ & $15.473 .199 .470,84$ & 41,54 & $13.438 .626 .173,13$ & 37,08 \\
$\begin{array}{c}\text { Competitividade } \\
\text { (EC) }\end{array}$ & $2.901 .344 .347,86$ & 60,30 & $6.653 .578 .471,69$ & 17,86 & $10.334 .570 .581,75$ & 28,52 \\
\hline
\end{tabular}

Fonte: Elaboração própria tendo por base dados do Aliceweb2 e UN-Comtrade.

A Tabela 4 mostra os resultados obtidos com o cálculo do modelo CMS de "segundo nível" para as exportações de RNNR desagregadas por capítulo do SH. De modo geral, no Período I, não se observa padrão claro que determine acréscimo ou decréscimo das exportações brasileiras dos RNNR de maneira desagregada; contudo, no Período II, observa-se uma clara evidência de que o ECCM foi o principal responsável pelas exportações destes recursos. No Período II, observa-se também que o ECPE foi relevante para explicar as exportações brasileiras de RNNR de maneira desagregada, já que a maioria dos capítulos estudados apresentou valores positivos e expressivos para este efeito, exceto para o caso das exportações brasileiras de alumínio e suas obras (capítulo 76), em que o ECPE contribuiu negativamente. Destaca-se ainda que, no Período II, o EC foi importante para explicar a variação das exportações brasileiras de minérios, escórias e cinzas (capítulo 26); de combustíveis minerais, óleos minerais e produtos da sua destilação, matérias betuminosas e ceras minerais (capítulo 27); de obras de ferro fundido, ferro ou aço (capítulo 73); de cobre e suas obras (capítulo 74); e de estanho e suas obras (capítulo 80). Este fato mostra que mesmo durante os anos de valorização do câmbio e, consequentemente, de maiores preços dos produtos exportados, o Brasil aumentou a competitividade para essas categorias de produtos. De modo geral, o crescimento das exportações brasileiras de RNNR no Período II (2004-2008) resultou principalmente 
do crescimento do comércio mundial e do fato de o Brasil ter os RNNR demandados pelo mundo naquela época.

Tabela 4 - Modelo Constant Market Share de segundo nível para a variação das exportações brasileiras de RNNR desagregadas por capítulos.

\begin{tabular}{|c|c|c|c|c|c|c|}
\hline \multicolumn{7}{|c|}{ Período I (2000 - 2003) } \\
\hline & \multicolumn{2}{|c|}{$\begin{array}{c}\text { Ef eito Crescimento do Comércio } \\
\text { Mundial (ECCM) }\end{array}$} & \multicolumn{2}{|c|}{$\begin{array}{l}\text { Efeito Composição da Pauta de } \\
\text { Exportacões (ECPE) }\end{array}$} & \multicolumn{2}{|c|}{ Efeito Competitividade (EC) } \\
\hline Capítulo & Variação em US\$ F OB & em \% & Va riação em USS FOB & em $\%$ & Variação em US\$ F OB & em \% \\
\hline 25 & $54.172 .258,21$ & 44,36 & $-6.132 .454,17$ & $-5,02$ & $74.089 .861,96$ & 60,66 \\
\hline 26 & 614.701 .488 .81 & 158.07 & 49.858 .771 .77 & 12.82 & -275.672 .781 .58 & -70.89 \\
\hline 27 & $171.539 .316,64$ & 5,94 & $-11.371 .096,64$ & $-0,39$ & $2.727 .682 .010,00$ & 94,45 \\
\hline 72 & 648.759 .955 .38 & 51.22 & 341.888 .768 .42 & 26.99 & 275.930 .226 .21 & 21.79 \\
\hline 73 & 109.122 .572 .57 & 80.70 & 40.752 .308 .89 & 30.14 & -14.650 .543 .46 & -10.83 \\
\hline 74 & $25.971 .495,83$ & 201,28 & $-27.414 .189,74$ & $-212,46$ & $14.346 .079,92$ & 111,18 \\
\hline 75 & $30.544 .166,11$ & $-128,21$ & $-13.376 .002,94$ & 56,15 & $-40.992 .178,17$ & 172,06 \\
\hline 76 & $281.184 .228,77$ & 1993,76 & $-57.464 .364,02$ & $-407,46$ & $-209.616 .673,74$ & $-1486,31$ \\
\hline 78 & 88.420 .59 & -58.33 & -82.593 .80 & 54.49 & -157.402 .79 & 103.84 \\
\hline 79 & $5.459 .380,67$ & 20,02 & $-9.716 .566,05$ & $-35,63$ & $31.526 .094,39$ & 115,61 \\
\hline 80 & 6.613 .133 .82 & -37.66 & -6.799 .010 .64 & 38.72 & -17.374 .620 .18 & 98.94 \\
\hline \multirow[t]{3}{*}{81} & $6.012 .828,53$ & $-371,91$ & $-6.491 .597,94$ & 401,53 & $-1.137 .961,59$ & 70,39 \\
\hline & \multicolumn{4}{|c|}{ Período II (2004-2008) } & & \\
\hline & \multicolumn{2}{|c|}{$\begin{array}{c}\text { Ef eito Crescimento do Comércio } \\
\text { Mundial (ECCM) }\end{array}$} & \multicolumn{2}{|c|}{$\begin{array}{l}\text { Efeito Composição da Pauta de } \\
\text { Exportacões (ECPE) }\end{array}$} & \multicolumn{2}{|c|}{ Efeito Competitividade (EC) } \\
\hline Capítulo & Variação em US\$ F OB & em $\%$ & Va riação em USS FOB & em $\%$ & Variação em US\$ F OB & em \% \\
\hline 25 & 352.270 .037 .68 & 120.42 & 169.637 .921 .24 & 57.99 & -229.374 .780 .92 & -78.41 \\
\hline 26 & $3.873 .927 .998,97$ & 28,72 & $7.903 .191 .723,91$ & 58,59 & $1.712 .362 .490,12$ & 12,69 \\
\hline 27 & 3.270 .890 .554 .33 & 22,93 & 4.333 .021 .370 .11 & 30,37 & 6.663 .491 .139 .56 & 46,70 \\
\hline 72 & $4.963 .270 .171,07$ & 80,89 & $2.109 .243 .625,96$ & 34,37 & $-936.426 .105,03$ & $-15,26$ \\
\hline 73 & 756.388 .205 .38 & 63,62 & 407.446 .767 .82 & 34.27 & 25.095 .537 .80 & 2,11 \\
\hline 74 & $206.618 .827,49$ & 28,49 & $187.643 .518,93$ & 25,87 & $331.087 .612,58$ & 45,65 \\
\hline 75 & 180.218 .763 .51 & 166.64 & 30.504 .729 .03 & 28.21 & -102.573 .796 .54 & -94.84 \\
\hline 76 & $1.382 .688 .488,27$ & 153,13 & $-74.221 .093,70$ & $-8,22$ & $-405.489 .341,57$ & $-44,91$ \\
\hline 78 & $707.511,44$ & 87,90 & $732.591,30$ & 91,02 & -635.235 .73 & $-78,92$ \\
\hline 79 & 46.324 .319 .85 & 162.15 & 3.963 .619 .84 & 13.87 & -21.718 .365 .69 & -76.02 \\
\hline 80 & $34.564 .816,42$ & 53,25 & $6.270 .524,55$ & 9,66 & $24.075 .951,03$ & 37,09 \\
\hline \multirow[t]{3}{*}{81} & 54.102 .912 .06 & 124.23 & 20.017 .186 .45 & 45.96 & -30.569 .648 .51 & -70.19 \\
\hline & \multicolumn{4}{|c|}{ Período III (2009 -2012) } & \multirow{2}{*}{\multicolumn{2}{|c|}{ Efeito Competitividade (EC) }} \\
\hline & \multicolumn{2}{|c|}{$\begin{array}{c}\text { Ef eito Crescimento do Comércio } \\
\text { Mundial (ECCM) }\end{array}$} & \multicolumn{2}{|c|}{$\begin{array}{c}\text { Efeito Composição da Pauta de } \\
\text { Exportacões (ECPE) }\end{array}$} & & \\
\hline Capítulo & Variacão em US\$ F OB & em $\%$ & Va riacão em USS FOB & em $\%$ & Variacão em USS F OB & em \% \\
\hline 25 & 186.996 .232 .56 & 109.46 & 97.906 .098 .72 & 57.31 & -114.071 .507 .29 & -66.77 \\
\hline 26 & $4.514 .877 .789,94$ & 24,03 & $7.563 .139 .586,19$ & 40,25 & $6.713 .259 .958,87$ & 35,73 \\
\hline 27 & 4.266 .355 .479 .50 & 33,30 & 6.303 .120 .713 .99 & 49,20 & $2.242 .297 .438,51$ & 17,50 \\
\hline 72 & $2.100 .245 .629,09$ & 52,67 & $207.979 .120,05$ & 5,22 & $1.679 .482 .047,86$ & 42,12 \\
\hline 73 & 547.226 .173 .53 & 1113,54 & -202.532 .139 .53 & $-412,13$ & -295.551 .139 .00 & -601.41 \\
\hline 74 & $187.190 .976,76$ & 169,62 & $151.001 .595,03$ & 136,83 & $-227.833 .624,79$ & $-206,45$ \\
\hline 75 & 68.937 .586 .47 & 26.84 & 25.642 .222 .81 & 9.98 & 162.307 .196 .72 & 63.18 \\
\hline 76 & $526.940 .125,55$ & $-259,88$ & $16.176 .835,58$ & $-7,98$ & $-745.878 .924,13$ & 367,86 \\
\hline 78 & $201,441,03$ & 8,08 & $-79.337,18$ & $-3,18$ & $2.370 .079,16$ & 95,10 \\
\hline 79 & $31.041 .302,52$ & 241,71 & $-7.414 .608,20$ & $-57,74$ & $-10.784 .317,32$ & $-83,97$ \\
\hline 80 & 15.248 .259 .20 & 16,09 & 14.465 .085 .60 & 15,26 & 65.047 .452 .20 & 68.64 \\
\hline 81 & $20.810 .124,96$ & 13,52 & $18.029 .398,96$ & 11,71 & $115.117 .522,08$ & 74,77 \\
\hline
\end{tabular}

Fonte: Elaboração própria tendo por base dados do Aliceweb2 e UN-Comtrade.

No Período III, o ECCM e o ECPE foram relevantes para explicar as variações positivas das exportações de todos os RNNR, desagregadas por capítulos, exceto para alumínio e suas obras (capítulo 76); obras de ferro 
fundido, ferro ou aço (capítulo 73); chumbo e suas obras (capítulo 78); e zinco e suas obras (capítulo 79). Contudo ressalta-se que, no caso das exportações de alumínio e suas obras (capítulo 76), o valor do ECPE de $-7,98 \%$ indica que a variação negativa das exportações de tais recursos não foi explicada por tal efeito. Ademais, o EC não foi relevante para explicar a variação das exportações brasileiras de enxofre, terras e pedras, gesso, cal e cimento (capítulo 25); de obras de ferro fundido, ferro ou aço (capítulo 73); de cobre e suas obras (capítulo 74); e de zinco e suas obras (capítulo 79).

\section{Conclusões}

O Brasil apresentou Vantagens Comparativas Reveladas para as exportações de RNNR e Efeito Competitividade positivo nos três períodos de análise. Entretanto, os resultados indicaram que as vantagens comparativas reveladas estão concentradas em duas categorias de produtos, que são minérios, escória e cinzas (capítulo 26) e ferro fundido, ferro e aço (capítulo 72) e que o Efeito Competitividade foi dominante apenas no período de significativa desvalorização cambial. O principal fator responsável pelo crescimento das exportações brasileiras de RNNR no período 2004-2012 (Períodos II e III) não foi a competitividade, mas sim a composição da pauta de exportações brasileiras, concentrada em categorias de produtos cuja demanda internacional se manteve aquecida durante esse período. Ademais, o Efeito Competitividade foi negativo no Período I (2000 - 2003) para o capítulo 26 e no Período II para o capítulo 72. Dessa forma, a abundância em tais recursos faz com que o Brasil se posicione como um grande exportador, porém nem sempre o país consegue manter ou elevar sua posição competitiva no mercado internacional.

É relevante notar ainda que o Brasil apresentou desvantagens comparativas reveladas para a categoria de combustíveis minerais, óleos minerais e produtos da sua destilação, matérias betuminosas, e ceras 
minerais (capítulo 27) durante todo o período analisado. No entanto, o aumento contínuo no valor do VCR concomitantemente ao Efeito Competitividade positivo para os três subperíodos indica que o Brasil tem galgado espaço no mercado internacional e pode ser tornar um grande exportador desses produtos. Por outro lado, os resultados mostraram que o Brasil perdeu competitividade nas exportações de alumínio e suas obras (capítulo 76) durante o período e, a partir de 2010, apresentou desvantagens comparativas nas exportações desses produtos.

Por fim, a combinação de vantagens comparativas reveladas concentradas em poucas categorias de produtos com crescimento das exportações, explicado principalmente pela composição da pauta exportadora, pode ser um cenário preocupante em períodos de baixo crescimento mundial.

\section{Referências}

BRASIL. Ministério do Desenvolvimento, Indústria e Comércio Exterior (MDIC). Aliceweb2. Disponível em: <http://aliceweb2.mdic.gov.br/>. Acesso em: jan./fev./mar.2012.

CHANG, M. S. Exportações brasileiras para a China e o Japão: padrões de especialização e competitividade. 2011. 123 p. Dissertação (Mestrado em Economia Aplicada) - Escola Superior de Agricultura "Luiz de Queiroz”, Universidade de São Paulo, Piracicaba, 2011.

CORONEL, D. A. Fontes de crescimento e orientação regional das exportações brasileiras do complexo soja. 2008. 113 p. Dissertação (mestre em Agronegócios) - Centro de Estudos e Pesquisas em Agronegócios, Universidade Federal do Rio Grande do Sul, Porto Alegre, 2008.

CORONEL, D. A.; MACHADO, J. A. D.; CARVALHO, F. M. A.; ILHA, A. S.; WAQUIL, P. D. Vantagens comparativas reveladas e orientação regional das exportações do complexo de soja brasileiro. ln: CONGRESSO DA SOCIEDADE BRASILEIRA DE ECONOMIA, 
ADMINISTRAÇÃO E SOCIOLOGIA RURAL, 46., 2008, Rio Branco, 2008. Anais...Rio Branco: SOBER, 2008. Disponível em <http://www. sober.org.br/palestra/9/253.pdf $>$. Acesso em jan. 2012.

DAVIS, G. A. Trade in Mineral Resources. World Trade Organization: Staff Working Paper ERSD-2010-1. Geneva, 2010.

DIETER, M.; ENGLERT, H. Competitiveness in the global forest industry sector: an empirical study with special emphasis on Germany. European Journal of Forest Research, v.126, p. 401-412, Nov. 2006.

\section{DIZ, L. A. C. Competitividade internacional das exportações} brasileiras de manga e de uva. 2008. 96 p. Dissertação (Mestrado em Economia Aplicada) - Escola Superior de Agricultura "Luiz de Queiroz", Universidade de São Paulo, Piracicaba, 2008.

GOMES, I. M. B. Segmento brasileiro de polpa celulósica: evolução, competitividade e inovação. 2011.155 p. Tese (Doutorado em Economia Aplicada) - Escola Superior de Agricultura "Luiz de Queiroz", Universidade de São Paulo, Piracicaba, 2011.

HARRIS, J. M. Non renewable Resources: Scarcity and Abundance. $\ln$ : . Environmental and Natural Resource Economics: A Contemporary Approach. $2^{\text {nd }}$ ed. Houghton Mifflin, 2006.chap. 12, p. 257-278.

HARTWICK, J. M.; OLEWILER, N. D. Non renewable Resource Use: The Theory of Depletion. ln: . The Economics of Natural

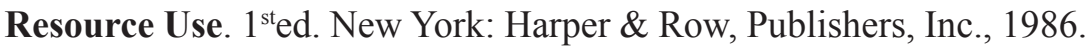
chap.3, p. 49-77.

KRUGMAN, P.; OBSTFELD, M. Recursos, vantagem comparativa e distribuição de renda. $\ln$ : Economia Internacional: teoria e política. Tradução de Eliezer Martins Diniz. 8. ed. São Paulo: Pearson Prentice Hall, 2010.cap.4, p. 41-64. 
MARKUSEN, J. R.; MELVIN, J. R.; KAEMPFER, W. H.; MASKUS, K. E. The Hecksher-Ohlin Model. In: International Trade: Theory and Evidence. International Edition.McGraw-Hill, 1995.chap. 8, p. $98-126$.

RIBEIRO, H. M. D. Fatores Relevantes no Desempenho Brasileiro no Mercado Internacional de Pedras Preciosas. 2008. 89 p. Dissertação (Mestrado em Economia Aplicada) - Departamento de Economia, Universidade Federal de Viçosa, Viçosa, 2008.

SEREIA, V. J.; NOGUEIRA, J. M.; CAMARA, M. R. G. As exportações paranaenses e a competitividade do complexo agroindustrial. Revista Paranaense de Desenvolvimento, Curitiba, n.103, p. 45-59, jul./dez. 2002.

SILVA, F. A.; GOMES, M. F. M.; CORONEL, D. A.; GOMES, M. T. M. Competitividade das Exportações Brasileiras de Mamão, 1995 a 2008. Revista de Economia e Agronegócio, vol.9, n. 3, p. 393-420, mar. 2012.

SILVA, M. A. R. Economia dos Recursos Naturais. ln: MAY, P. H.; LUSTOSA, M. C.; VINHA, V. Economia do Meio Ambiente. Rio de Janeiro: Elsevier, 2006. p.33-60.

UNITED NATIONS STATISTICS DIVISION (UNSD). Database. Disponível em <http://comtrade.un.org/db/>. Acesso em jan./fev. 2012.

VITTI, A. Análise da competitividade das exportações brasileiras de frutas selecionadas no mercado internacional. 2009. 106 p. Dissertação (Mestrado em Economia Aplicada) - Escola Superior de Agricultura "Luiz de Queiroz”, Universidade de São Paulo, Piracicaba, 2009.

WOOD, A.; BERGE, K. Exporting manufactures: human resources, natural resources and trade policy. The Journal of Development Studies, London, v. 34, n.1, p. 35-59, Oct.1997.

WORLD TRADE ORGANIZATION (WTO). World Trade Report 2010: Trade in natural resources. Geneva, 2010.256 p. 
REVISTA DE ECONOMIA E AGRONEGÓCIO, VOL.11, $N^{\circ} 3$ 